\title{
The wheel and the cloister in the rule of seclusion: architectural elements or elements of a communication system?
}

\author{
Alice Palmieri ${ }^{1}$ \\ ${ }^{1}$ Department of Architecture and Industrial Design University of Campania 'Luigi vanvitelli', Italy.
}

Email: alicepalmieri@hotmail.com

\begin{abstract}
When Walter Benjamin describes Naples, he defines its architecture 'porous like this stone' assimilating the structural characteristic of the tuff to an architectural model, characterized by voids and openings that create an interpenetration between interior and exterior. These continuous breakthroughs also characterize the life of Neapolitans who are used to living the street as part of social life. Right in the historical centre, where these dynamics are deeply present, there are some cloistered convents that by definition are closed to the city. This paper investigates sacred architecture not as a celebrative space, but as a place of living for religious communities. The focus is on the monasteries: peculiar structures deeply marked in the architecture by the need for confidentiality and therefore to create filters, physical and visual, with the rest of the urban area. The convents of Naples, through the wheels (intended for the passage of offerings) and through the cloisters, establish a relationship with the city that over the centuries has changed with a progressive opening to the inhabitants who are now allowed to get closer to these realities. The research finally deepens the architecture of the convent of Santa Maria in Gerusalemme, commonly known as the monastery of 'the Thirty-three', adjacent to the historical hospital of the Incurabili with which it shares its origins since both were founded by the Venerable Maria Lorenza Longo. Despite the closure and the high fence wall, the presence of the monastery is very strong: it is a reference and a listening point, where the ancient wooden wheel still represents a way of communication between the residents of the district and the nuns. In the same way, the cloister and the refectory have transformed their function over the centuries, becoming spaces for public events, while remaining in line with the rules of the Order.
\end{abstract}

The study of the structure and dynamics of communication from/to the convent proposes a reflection on the transformations of religious architecture in the urban context and on the changes in language and meaning of the architectural elements characterizing the monastery.

(C) 2019 The Authors. Published by IEREK press. This is an open access article under the CC BY license (https://creativecommons.org/licenses/by/4.0/).

Keywords

Monastery; Cloister; Communication; Perception

\section{Introduction}

The numerous Neapolitan monastic structures represent a very interesting field of study for the understanding of two themes common to all monasteries: how to inhabit a sacred space and communication in the monastic dimension. The monasteries of Naples, through the cloisters and through the wheels (first intended for the passage of offers, now mainly for listening) establish a relationship with the city in different ways. A relationship that over the centuries has changed with a progressive opening to the inhabitants who are now allowed to approach these realities. This paper 
explores the history of the Monastery of Santa Maria in Gerusalemme, a community of Capuchin Poor Clares who reside in the ancient center of the city of Naples, investigating its current condition and the theme of living a sacred space in the dimension of cloistered life.

\section{Origin and development of the Capuchin Monastery of "the Thirty-three" Poor Clares}

The monastery of Santa Maria in Gerusalemme was founded in 1535 by Maria Lorenza Longo. A few years earlier she had created the hospital of the Incurables (adjacent to the cloister) where the sick abandoned and refused by other hospitals in the city were welcomed. At the time the founder, an active representative of the rule of St. Chiara, revolutionized this part of the city. In fact, the monastery and the "Incurables" strongly characterize the upper decumanus, in the district of Saint Lorenzo, and they arise in a crucial centre of the Greek-Roman Naples. The monastery is located on an insula in front of the Odeon, not far from the ancient Neapolis theatre, therefore in a rich area of the ancient city. The origin of the monastery is deeply linked to the hospital: in 1530 Maria Lorenza Longo welcomed in some rooms inside the hospital a few Capuchin Friars to ensure spiritual and material assistance to the patients, forgotten and abandoned by society of the time. In 1533 the same structure hosted the Teatini fathers, who later moved into other properties in vico degli Incurabili (now via Luciano Armanni) purchased by M.L. Longo. San Gaetano da Thiene here built the church of "Santa Maria della Stalletta" (precisely because it was built in a stable) which then took the name of "Santa Maria del Presepe". In fact, as reported in a text of the eighteenth century entitled "Life of St. Gaetano Tiene", following a vision of the Madonna, the Saint created a crib in the chapel (the first "modern" Neapolitan crib) with wooden figures dressed in the style of the time. Thanks to the help of San Gaetano, Maria Lorenza Longo received the seal of foundation of Pope Paul III, which authorized her to build a monastery for a community of nuns under the observance of the first rule of Saint Chiara. Because of the influx of vocations, Pope Paul III himself granted the increase in the number of nuns to "thirty-three", an epithet that still recognizes the sisters of this cloister today. It was therefore necessary to have more space for monastic life and in 1538, following the transfer of the Theatine fathers, M.L. Longo moved her community to the convent of Santa Maria della Stalletta. Documented in the archive ${ }^{1}$, this passage was possible thanks to a clause wanted by the foundress: if the fathers left these spaces, they would have passed by right to the nascent monastery of Santa Maria in Gerusalemme. Since these spaces also proved insufficient to accommodate thirty-tree nuns, the Capuchins acquired further adjacent properties, increasing the dormitory and creating a garden.

Still today, walking along the perimeter of the high walls that enclose the monastery, one can perceive the extreme irregularity of the construction that reveals the complex and articulated history of this "Neapolitan Jerusalem" (that with its name reveals the desire of the founder of a pilgrimage to the Holy Land). The monastery in its architecture followed the criteria of the Capuchin friars' convents and had two cloisters: a colonnaded one on the side of Via Pisanelli and a simpler one on the side of Via Luciano Armanni, which served as a vegetable garden. The complex was developed on two levels: work spaces were arranged around the cloisters (wash-tubs, kitchen, woodshed ...). This organization favoured the fraternal relationship between the sisters, reflecting the Capuchin spirituality in the architectural space. For this reason the cloister was the real centre, the living space that allowed the sharing of activities between the sisters. On the upper floor, around the perimeter of the cloister, the most private rooms were placed: the dormitory, the infirmary and a chapel. At the time, the church was located in front of the current entrance from Via Pisanelli: it was a small church with a single nave, in full Capuchin style, with a painting on the altar representing the presentation of Jesus to the Temple. 


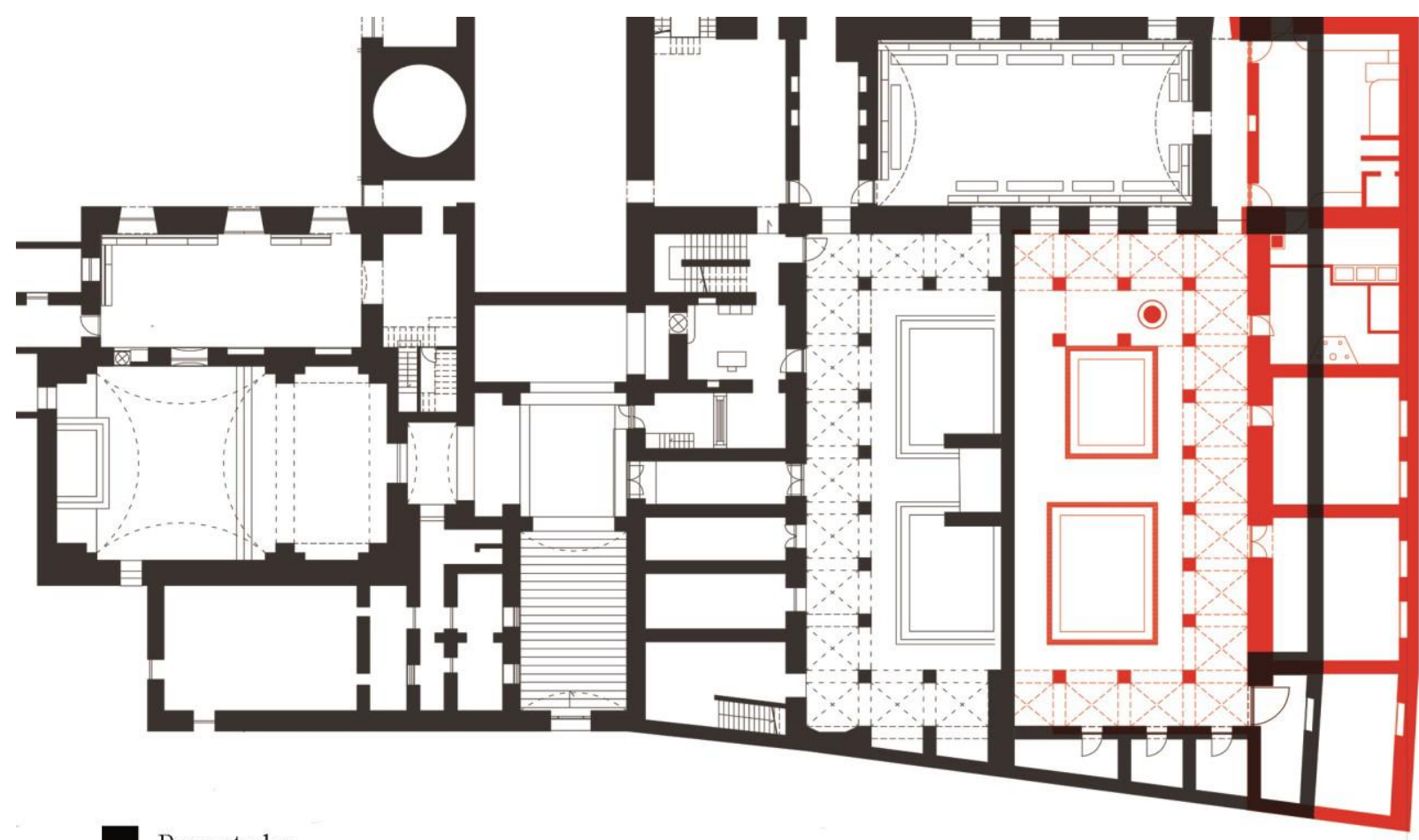

Present plan

Demolished surface

Figure 1. Overlap between the current plan and the situation before the demolition of the cloister

In 1623 there was a further enlargement of the Monastery thanks to the purchase of a palace in Via Pisanelli. The building was demolished and the present church was built in its place. This had the same characteristics as the previous one: a single nave, a few simple decorations, at the top the choir for the nuns and an opening from which they could receive communion. Obviously this sacred space must also adapt to the specific function of the cloister and therefore the confidentiality of the nuns is the regulator of all architectural forms. For example, behind the high altar there was a staircase that allowed the priest to go to the confessional to communicate privately with the sisters. The same system had also been used for the chapel of the infirmary in order to avoid access to the cloister. The church was consecrated in 1764, decorations in wood and stucco were added and the Neapolitan artisan flooring was laid, which recalls the majolica of the cloister of Santa Chiara.

Then, between the 16th and 18th centuries, the little Neapolitan Jerusalem underwent many transformations, but its community remained strong and grew in faith. In fact, in 1810 with a decree of Murat and later in 1866, the laws of suppression of religious orders had the objective of making these communities of consecrated persons disappear, but the "thirty-three" were able to protect their fraternity and today are the only order in Naples that has always remained there where it originated.

In 1903, some rooms, including the refectory and the cloister, were required. A high wall was erected to separate the monastery from the expropriated premises and still divides the area of the cloister into two portions. The smaller part is part of the monastery, but the rest is unusable by the nuns for reasons of visibility from the street and confidentiality. 
Palmieri/ Proceedings of Science and Technology

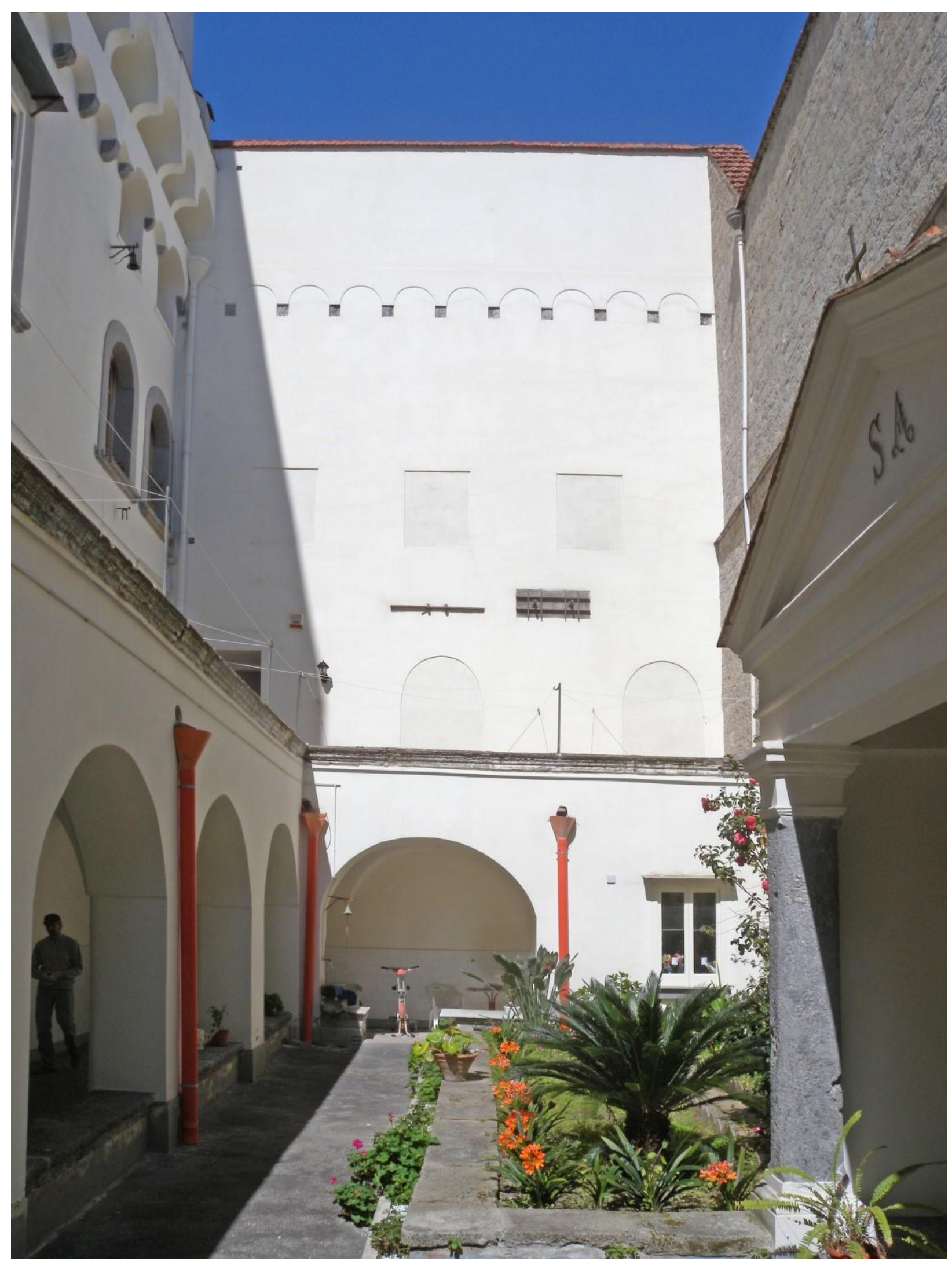

Figure 2. The part of the cloister on the side of the monastery and the partition wall 


\section{Living in the cloistered space}

For many people it's difficult to understand cloistered life, it's difficult to understand the choice of living all one's life in the same place, with the same people, without being able to go out. But even more difficult is to imagine that internal space: a sacred space and yet a living space. A large house for a small community of consecrated persons who have needs for privacy and also a necessity of sharing. In order to understand the living and perceptual dynamics of a complex and -in a certain sense mysterious- space like that of a monastery, I had the opportunity to do an interview with the youngest nun of the convent of the "Thirty-three". Sister Paola is a young nun who entered the cloister immediately after graduating in architecture. Her point of view, as a nun and architect, is a precious tool for investigating the perception of space, inside and outside, of a sacred and inhabitable place at the same time. I asked her some questions to deepen these issues.

Me: Hi, Sister Paola! Thank you for taking the time to talk to me. It is a great privilege to be able to know your peculiar point of view that can help to understand the cloistered space and its perception. The first question I want to ask you is about your approach to the monastery. How did you get to this new home?

There are several thresholds that lead from the city into the space inhabited by nuns. Having slowly crossed the various thresholds has slowly given prominence to the difference between the outside and the inside. Between the "race" outside and the "race" inside! Immediately after crossing the innermost threshold, the one that opened the reserved space, separated, thinned for a different life, I had a plan in my hands! What better tool for me to make contact with a totally new space? Knowledge was not exhausted in a single observation but needed time!

The first step was to "orient myself"! The reserved space, separated and inhabited by the monastic sorority was a space that continuously opened up! I could almost say that it still continues to open up, because it is a "container" with an almost cellular structure in which everything is present, in which some elements are visible and others hidden, some easily identifiable and others to be discovered. Having always new eyes and new glances is a foundation of living in the cloistered space!

I don't like the term cloistered/claustral because it is closely linked to the image of life revolving around the cloister and our life, strictly speaking about our sorority in this monastery, doesn't revolve around the cloister, simply because there isn't one! For about a century, sorority has had to be adapted to a space that has assumed over time a spatial configuration totally different from that held for a classic monastic structure, where the major rooms of service to sorority rotate around the cloister. In this monastery life had to develop in large part in height! A solicitation that brings me back to the development of many urban agglomerations, as in the city in which we live!7

Me: so how did the approach to this new space happen? How does your perception of the interiors change with the passing of time?

This was the second step: "take the measurements"! The space I was getting to know and exploring did not have the dimensions of a single-family house or in any case of environments that seemed reserved, preserved; unlike what I had imagined, the space in which my body moved was spacious, abundant, airy, capable of containing, a real surprise for the senses. Despite having had the experience of living in large spaces, spaces in which you don't touch the roof, spaces in which you lose yourself by looking up and thinking, for example, of European cathedrals, as well as museum spaces, spaces of school education, living in a space that opens up continuously, which reveals dimensions that are not "legislative standards" is of great impact for the person! It should be borne in mind that large spaces are now reserved for experience limited in time, they are often temporary experiences. The third step is "recalibrating perception"! To recalibrate the sight, the perspective, to be able to live serenely spaces other than the ordinary spaces of life. The spaces of "ordinary life" are at "human heights": they are spaces in which one doesn't lose oneself and in which hot and cold are not dispersed and where one listens easily and voices are not confused by great distances. Recalibrating perception in a living space that has super-human dimensions is the great "challenge": it is a matter of living in a sacred place, a sacred space that is an art that is learned every day! To live in a monastic space it is necessary 
to continuously rework perception, and this is an operation that does not end in time, although the body slowly has the ability to recalibrate perception every day, depending on the spaces that host it and the functions it performs!

Me: I want to conclude by asking for your relationship with the city. Considering that we are in the historic centre, how do you feel about the urban space around you? What is your perception of the external space?

We come to the fourth step: "discover the outside"! The space of the monastery is made up of full and empty spaces, open and closed spaces, communication spaces and spaces that delimit communication. The architectural space suggests its function and proposes a different way of living. There are two places where the encounter with the outside takes place, where the architectural boundary can be established and much deeper spiritual boundaries can be crossed! The architectural boundary does not become a barrier but sets a sign. The discovery and perception of the parlour and the wheel deal with all this! Even for these places (which I already knew before crossing the inner threshold) the perception has changed for me. They are not places where we spend more time than the time of the encounter, so it is a place of encounter but the "life" of sorority does not take place there. Meeting in a border/boundary place gives many times the feeling to those who are outside, that our "life" is there and, rightly, in that place you feel a sense of "closure". At the same time, for me it becomes a "sponge" space, an empty space ready to be filled! The wheel, a void in the wall that separates the inside from the outside, is filled with a wooden structure that suggests the name for the form and function. There is the encounter of voices and scents, an encounter lived on the basis of two very strong senses, hearing and smell.

Another step is to discover oneself "inside the city"! One of the peculiarities of the Monastery Santa Maria in Gerusalemme is the fact that it is located inside the city, a little higher than the heart of Ancient Naples. This characteristic makes the architectural, cultural and social bond very strong! The monastery is a separate space within the city, retains its integrity and strong identity but still makes it possible that the city penetrates inside thanks to sound waves, which are sometimes music, other noises, voices, colours of the sky and the houses around, the scents that go beyond any architectural boundary! Sorority also in this way participates in the life of the city, with a very strong sensory perception!

Me: Thank you, Sister Paola, for your testimony. Your reflections, guided by the eyes of an architect and the heart of a nun, took me on a journey inside the monastery. One step at a time. Thank you very much for your collaboration!

\section{Conclusion}

The monastery of "the Thirty-three" has a complex history made up of complicated phases of development and transformation. Even today, the sorority is still affected by the "mutilation" of the cloister, only partially usable by the nuns. This community of women lives its cloister in full respect of the rule of Saint Chiara, in privacy and simplicity, but has a strong impact on the territory. Living in the neighbourhood you have the perception of how this structure, apparently closed, is a reference for the local community. And thanks to the precious collaboration of Sister Paola, it is also possible for us to understand the complexity of the interior space, made up of dimensions, spaces, permanent yet changing views. The monastery represents a transformed reality that still wants to be transformed, showing how the sacred space, just like the space of the city, is constantly evolving.

\section{References}

De Seta, C. (1973). Storia della città di Napoli: Dalle origini al Settecento. Editore Laterza, Roma.

Margiotta, M.L. (2000). Il giardino sacro: Chiostri e giardini della Campania. Editore Electa, Napoli.

Valerio, A. (2007). I luoghi della memoria. Istituti religiosi femminili a Napoli dal IV al XVI secolo. Voyage pittoresque, Napoli. 